\title{
BMJ Open Questionnaire survey on women's views after a first caesarean delivery in two tertiary centres in Ireland and their preference for involvement in a future randomised trial on mode of birth
}

\author{
Gillian Ryan (D , ${ }^{1,2}$ Kate C O Doherty, ${ }^{3}$ Declan Devane, ${ }^{4}$ Fionnuala McAuliffe, $, 3,5$ \\ John Morrison ${ }^{1,2}$
}

To cite: Ryan G, 0 Doherty KC, Devane D, et al. Questionnaire survey on women's views after a first caesarean delivery in two tertiary centres in Ireland and their preference for involvement in a future randomised trial on mode of birth. BMJ Open 2019;9:e031766. doi:10.1136/ bmjopen-2019-031766

- Prepublication history and additional material for this paper are available online. To view these files, please visit the journal online (http://dx.doi. org/10.1136/bmjopen-2019031766).

Received 17 May 2019 Revised 05 September 2019 Accepted 09 September 2019

Check for updates

(c) Author(s) (or their employer(s)) 2019. Re-use permitted under CC BY-NC. No commercial re-use. See rights and permissions. Published by BMJ.

For numbered affiliations see end of article.

Correspondence to

Dr Gillian Ryan;

gillian.ryan@nuigalway.ie

\section{ABSTRACT}

Objective To assess the views of women after a first caesarean section (CS) on their birth experience, preference for future mode of birth and willingness to participate in a randomised controlled trial on mode of birth in a future pregnancy.

Design Questionnaire survey.

Setting Two tertiary maternity centres Ireland, Galway University Hospital, Galwayand the National Maternity Hospital, Dublin.

Participants Women with one previous CS.

Methods Eligible women consented to participate, and postal surveys were forwarded. Results were collected and analysed. Results were compared between women who had elective operations and women who had emergency operations.

Primary outcome measures The satisfaction levels of women after a first caesarean, their preference for mode of birth in a future pregnancy and their willingness to participate in a randomised trial on mode of birth.

Results There were 347 completed surveys of 633 women who consented to participate (54.8\%), of whom 285 and 62 had emergency and elective caesarean deliveries, respectively. In general, satisfaction ratings with the delivery were greater than $90 \%$, with similar levels of satisfaction with the care received from doctors and midwives. Women who an emergency procedure expressed lower satisfaction levels with the information about the caesarean and the debriefing received afterwards than women who had a planned operation $(p<0.05)$. For future mode of birth, 39.5\% expressed a preference for vaginal birth after caesarean (VBAC) in a subsequent pregnancy, and $80 \%$ said they would consider involvement in a randomised trial in a future pregnancy.

Conclusion Debriefing and counselling women after a CS is an important part of pregnancy care and can significantly impact on a woman's overall birth experience. A significant proportion of this cohort considered VBAC as a future birth option. These data indicate that a randomised trial on mode of birth after caesarean would be viewed positively by women in our population.

\section{Strengths and limitations of this study}

- This study assesses the satisfaction levels of women having a first caesarean section on various aspects of care and investigates whether the type of caesarean delivery influences their preference for future mode of birth and their willingness to participate in a randomised trial on mode of birth in a future pregnancy.

- The strengths of this study include the large number of women recruited across two different geographical sites.

- The evaluation of future birth preferences and willingness to participate in a randomised controlled trial on mode of birth is a topic on which there are minimal data in a European obstetric population.

- This analysis gives an overview of preference for future mode of birth and willingness to be involved in a trial on mode of birth, but we are unable to assess how this preference may change over time.

\section{INTRODUCTION}

Women who have had one previous caesarean section (CS) represent a significant proportion of all women presenting for antenatal care in pregnancy. ${ }^{2}$ For the majority of such women, the option of having either a vaginal birth after caesarean (VBAC) or a repeat elective caesarean section (ELSCS) is a focus of major discussion in a subsequent pregnancy. Many factors influence this decision, including the reason for the original CS, other obstetric variables, views of the attending obstetrician and, finally and most importantly, the views of the mother and her partner. ${ }^{13}$ This discussion includes attention to the risks and benefits of VBAC versus repeat ELSCS. ${ }^{3-8}$ Apart from these clinical issues, there are many geographical, ${ }^{1}{ }^{9-11}$ institutional, ${ }^{12}$ epidemiological 
and legal factors ${ }^{13}$ that influence VBAC rates worldwide. What is clear, however, is that VBAC attempt rates ${ }^{1}$ and VBAC rates ${ }^{1}$ have been declining significantly in recent years in developed countries. ${ }^{17}$ Apart from the clinical importance of this topic and the associated morbidity, increasing CS rates also place a significant burden on healthcare resources. ${ }^{1415}$

Notwithstanding the issues outlined previously, the evidence available for counselling a woman who has had one CS regarding her birth options in a future pregnancy is limited. Currently, the only data from randomised controlled trials (RCTs) of VBAC versus repeat ELSCS emanate from two trials, ${ }^{16}{ }^{17}$ totalling 320 women. Only one of these provided results on maternal and fetal outcomes, ${ }^{17}$ and the numbers were too small to generate any strong recommendations that might inform women's decision on mode of birth. A Cochrane review concluded that both options of VBAC and repeat ELSCS are associated with benefits and harms; however, the evidence for the magnitude of these outcomes was drawn from non-randomised studies and associated with potential bias, and therefore must be interpreted with caution. ${ }^{4}$ The need for further RCTs was emphasised. However, there remains doubt concerning the feasibility of such a trial and whether or not women would agree to randomisation. ${ }^{414}$ There are minimal data regarding women's views on this topic and none to our knowledge pertaining to a European population of expectant mothers. The aim of this study was to evaluate the views of women who had one previous CS regarding their experience of delivery, their preference for birth options in a future pregnancy, and finally, their willingness, or otherwise, to participate in a potential future RCT of VBAC versus repeat ELSCS.

\section{METHODS}

This study used a written questionnaire survey of women who had their first CS between January and August 2017 in two tertiary teaching hospitals in Galway University Hospital, Galway, Ireland, on the west coast, and the National Maternity Hospital, Dublin, on the east coast. Institutional review board approval was obtained at both sites (Galway University Hospital reference no. 1804 and National Maternity Hospital reference no. EC 37.2017). Eligible participants were identified using hospital-maintained computerised databases. Women were contacted by telephone or post for consent, and postal surveys were subsequently forwarded. Surveys were distributed over a 9-month period from September 2017 to March 2018 in an effort to capture the woman's views on a subsequent mode of birth within the first year after the index pregnancy. Exclusion criteria included women under 18 years of age and any women who had a perinatal loss (information received from the hospital databases). A patient interaction focus group was organised prior to the study with a number $(n=10)$ of women who recently had their first CS. Validation of the survey questions was a component of this meeting. In addition, telephone contact was made with a small number of participants $(n=20)$ after receipt of the survey to assess their understanding of the information included.

The following factors were included in the survey instrument: (1) the reason for the CS; (2) whether it was a planned or unplanned/emergency procedure; (3) women's satisfaction regarding (3.1) the statement that a CS was the best option for them at the time, (b) the care received from the obstetric team, (c) the care received from the midwifery team, (d) the information received prior to delivery regarding the CS and (e) the information/debriefing received after delivery regarding the CS; (4) women's preference for mode of birth in a future pregnancy; and (5) women's willingness or otherwise to participate in a future RCT of VBAC versus repeat ELSCS. Satisfaction scores obtained (1-5) were grouped into those from women who described themselves as satisfied (satisfaction rating 1-2) with their experience or those who were not satisfied (satisfaction rating 3-5). A copy of the survey form is in online supplementary file 1 and has been forwarded to the editorial board.

Demographic details, including maternal age, body mass index (BMI), gestation at delivery, parity and ethnicity, were ascertained from the hospital databases. Statistical analyses were performed using $\chi^{2}$ test and t-test as appropriate (IBM SPSS V.24). A $p$ value of $<0.05$ was considered as being statistically significant. A subgroup analysis was also performed between women who had a planned ELSCS and women who had an unplanned emergency caesarean section (EMCS).

\section{PATIENT AND PUBLIC INVOLVEMENT}

During the development of this questionnaire survey, women after a first CS were invited to take part in a focus group to share their experience surrounding their care at the time of CS and their preferences for future mode of birth. They were also invited to give their opinion on what information they felt was important to be collected for the survey. During the initial phase of the survey, responses were selected at random and patients were contacted to discuss their responses to the survey to ensure they had no comments on how to improve it. Once published, the data will be made available on both hospital sites, for antenatal clinic visits and for formal prenatal education classes.

\section{RESULTS}

A total of $n=734$ women were identified from the hospital databases as being eligible to participate in the survey, and $633 / 734(86.2 \%)$ consented to participate and were sent postal questionnaire surveys. There were 347/633 $(54.8 \% \%)$ completed survey forms returned for analysis: 154/242 (63\%) at Galway University Hospital and $193 / 391(49.4 \%)$ at the National Maternity Hospital, Dublin. Of these, $285 / 347(82.1 \% \%)$ had an EMCS, and $62 / 347(17.9 \%)$ had an ELSCS. The main reasons 


\begin{tabular}{|c|c|c|c|c|}
\hline & $\begin{array}{l}\text { Overall } \\
\text { group } \\
(\mathrm{N}=347)\end{array}$ & $\begin{array}{l}\text { EMCS } \\
(n=285)\end{array}$ & $\begin{array}{l}\text { ELSCS } \\
(n=62)\end{array}$ & $P$ value \\
\hline Para $>1$ & 86 & 56 & 30 & \\
\hline Para 1 & 261 & 229 & 32 & \\
\hline $\begin{array}{l}\text { Average age } \\
\text { (years) }\end{array}$ & 34.9 & 34.99 & 34.89 & ns \\
\hline $\begin{array}{l}\text { Average } \\
\text { BMI } \\
\left(\mathrm{kg} / \mathrm{m}^{2}\right)\end{array}$ & 25.9 & 25.95 & 25.43 & ns \\
\hline $\begin{array}{l}\text { Gestation at } \\
\text { delivery } \\
\text { (weeks }^{\text {+days }} \text { ) } \\
\text { Mean }\end{array}$ & $39^{+5}$ & $39^{+6}$ & $38^{+5}$ & $p<0.01$ \\
\hline $\begin{array}{l}\text { Nationality: } \\
\text { Irish }\end{array}$ & $\begin{array}{l}276 \\
(79.5 \%)\end{array}$ & $\begin{array}{l}227 \\
(79.6 \%)\end{array}$ & $\begin{array}{l}49 \\
(79.04 \%)\end{array}$ & \\
\hline Other & $71(20.5 \%)$ & $\begin{array}{l}58 \\
(20.35 \%)\end{array}$ & $\begin{array}{l}13 \\
(20.96 \%)\end{array}$ & \\
\hline
\end{tabular}

Patient demographic features show comparison of the emergency caesarean delivery group with the elective caesarean delivery group.

Statistical significance was taken as $\mathrm{p}<0.05$.

Para 1 indicates women after their first pregnancy. Para $>1$ indicates women in a second or subsequent pregnancy. BMI, body mass index; ELSCS, elective caesarean section; EMCS, emergency caesarean section; ns, not significant.

for CS were failure to progress in labour or failed induction of labour $(121 / 347,34.9 \%)$, abnormal fetal heart rate pattern $(108 / 347,31.1 \%)$, malposition (including breech presentation; 50/347, 14.4\%), other (including previous third-degree tear, maternal anxiety, previous shoulder dystocia, urinary incontinence; $35 / 347,10.1 \%$ ), maternal medical reason $(24 / 347,6.9 \%)$, failed instrumental delivery $(8 / 347,2.3 \%)$ and one where the woman was unsure of the indication for CS $(1 / 347,0.3 \%)$. There were 261 women who had CS in their first pregnancy (para 1), and 86 women had their first CS in a second or subsequent pregnancy (para $>1$ ). The demographic features of the groups are presented in table 1. The average maternal age was 34.9 years and the average BMI was $25.9 \mathrm{~kg} / \mathrm{m}^{2}$. The mean gestation at the time of birth was higher in the EMCS group than in the ELSCS group $\left(39^{+6}\right.$ weeks vs $38^{+5}$ weeks, respectively; $\left.\mathrm{p}=0.01\right)$. There were no other significant differences between the demographics of the groups.

A comparison of the results of the survey questions divided by women in the EMCS and ELSCS groups are presented in table 2 . The vast majority of women in both groups (95\%-96\%) were satisfied in general that CS was the most appropriate delivery option for them given their clinical circumstances. Replies to the question pertaining to the medical care provided revealed satisfaction levels of 92\%-98\%. Regarding midwifery care, satisfaction levels were $90 \%-93 \%$.

However, women in the EMCS group were less satisfied with the information received regarding the CS, both prior to delivery $(\mathrm{p}<0.05)$ and postnatally $(\mathrm{p}<0.01)$ (table 2$)$. The lowest rates of satisfaction overall $(54 \%)$ were experienced by women in the EMCS group regarding their views on the debriefing information they received postnatally. No difference was observed between hospital sites in relation to these levels of satisfaction.

In the overall cohort, $39.5 \%$ of women expressed a preference for VBAC in a subsequent pregnancy, and this was similar for women in the EMCS and ELSCS groups (table 3). The preference rate for repeat ELSCS overall was $31.7 \%$. The proportion of women who were undecided was $28.8 \%$. Approximately $80 \%$ of women in both groups said they would consider randomisation in a future pregnancy (table 3). These findings were similar among women across both hospital sites.

Women in the para 1 group had an EMCS rate of $87.7 \%$ compared with $65.1 \%$ in the para $>1$ group $(p<0.01)$. The women in the para 1 group were also less satisfied with the postnatal counselling received than those in the para $>1$ group $(55.6 \%$ vs $72.1 \%, \mathrm{p}<0.01)$. There was also a difference observed in the preference for future mode of birth, with $35.6 \%$ in the para 1 group expressing a preference for VBAC compared with $52.3 \%$ of women in the para $>1(\mathrm{p}<0.01)$. Despite this finding, there was no difference observed in the proportions who would consider involvement in a future randomised trial on mode of birth, para $1=82.4 \%$ and para $>1=76.7 \%(p=0.25)$.

Table 2 Patients' level of satisfaction by emergency caesarean delivery versus elective caesarean delivery

\begin{tabular}{|c|c|c|c|}
\hline & EMCS $(n=285)$ & ELSCS (n=62) & $P$ value \\
\hline Satisfied with medical care provided & $263(92.3 \%)$ & $61(98.4 \%)$ & ns \\
\hline Satisfied with information at the time of delivery & $250(87.8 \%)$ & $61(98.4 \%)$ & $\mathrm{p}<0.05$ \\
\hline $\begin{array}{l}\text { Satisfied with postnatal counselling and information about } \\
\text { caesarean }\end{array}$ & $154(54 \%)$ & $51(82.3 \%)$ & $p<0.001$ \\
\hline
\end{tabular}

Patient satisfaction levels show comparison of the emergency caesarean delivery group with the elective caesarean delivery group.

Statistical significance was taken as $\mathrm{p}<0.05$.

ELSCS, elective caesarean delivery; EMCS, emergency caesarean delivery; ns, not significant. 
Table 3 Preferences for future delivery

\begin{tabular}{|c|c|c|c|c|}
\hline & Overall group $(\mathrm{N}=347)$ & EMCS $(n=285)$ & ELSCS $(n=62)$ & $P$ value \\
\hline \multicolumn{5}{|c|}{ Preference for future mode of delivery } \\
\hline VBAC & 137 (39.5\%) & $114(40 \%)$ & $23(37.1 \%)$ & ns \\
\hline Undecided & $100(28.8 \%)$ & $88(30.9 \%)$ & $12(19.4 \%)$ & ns \\
\hline \multicolumn{5}{|c|}{ Would you consider involvement in an RCT of VBAC versus repeat ELSCS? } \\
\hline No & $66(19 \%)$ & $55(19.3 \%)$ & $11(17.7 \%)$ & ns \\
\hline
\end{tabular}

The table lists patient preferences for future mode of delivery and willingness to be involved in a future randomised trial of VBAC or elective repeat caesarean delivery.

Statistical significance was taken as $p<0.05$. ns=Not significant.

EMCS, emergency caesarean section; ELSCS, elective caesarean section.

$\mathrm{RCT}$, randomised controlled trial;VBAC, vaginal birth after caesarean;

\section{DISCUSSION}

Management of delivery for the woman who has had one previous CS is a controversial area of obstetric practice, with many factors influencing the decision to pursue either VBAC or repeat ELSCS, ${ }^{1} 1318$ as outlined earlier. However, it is well established that the view of the woman is paramount in arriving at a decision regarding mode of birth in these circumstances, ${ }^{19}$ and hence the focus of this study was on the satisfaction levels of women who had one CS regarding their past birth, and their plans or deliberations for a future birth. There are minimal data to our knowledge on this topic in a European obstetric population. The strengths of this study include the large number of women recruited across two different geographical sites, specific evaluation of future birth preferences and willingness to participate in an RCT on mode of birth, and finally, the level of concordance of the results across both sites. The limitations of this study are discussed further.

In this study, satisfaction with the delivery, that is, having had a CS, was in the region of $95 \%$ and was similar for both the EMCS and ELSCS groups. This is in contrast to other studies that have reported lower satisfaction rates for women who had unplanned CS procedures compared with women who had planned CS procedures. ${ }^{20}{ }^{21}$ We similarly observed high satisfaction rates, that is, greater than $90 \%$ with care providers. This study also assessed the level of satisfaction the women experienced in relation to information received at the time of CS and the postnatal debriefing provided. Unsurprisingly, women who had an EMCS reported a significantly lower satisfaction level with the information received at the time of delivery than women who had an ELSCS. This factor may well be related to the fact that the majority of these operations were performed intrapartum, as an emergency procedure. It is disappointing that only $54 \%$ of women in the EMCS group were satisfied with postnatal counselling and debriefing. Specific comments from women included 'I found the aftercare disappointing', 'there was no counselling or information given about what happened or what to expect', 'my experience was very frightening, and the reason discussed only briefly' and 'I still have unanswered questions about my delivery'. The usual practice at both hospital sites for counselling women after their first CS includes a number of approaches. The women and their partners are debriefed in the first 24 hours by the medical obstetric team involved. Depending on circumstances, and if it reflects patient preference, a hospital postnatal visit is arranged for 6 weeks after the delivery. The NICE guideline on CS states that women after a CS should be given the opportunity to discuss the reasons for the CS and be provided with both verbal and printed information about future birth options. ${ }^{22}$ Despite this recommendation, there remains a paucity of guidelines surrounding the best practice for postnatal debriefing, and similarly, there is a lack of guidance regarding postnatal follow-up for women who may have had more difficult or traumatic childbirth experiences.

Regarding future mode of birth, $39.5 \%$ of the overall group expressed a preference for VBAC, while $31.7 \%$ had a preference for repeat ELSCS and 28.8\% were undecided. The statistic of approximately $40 \%$ of women expressing a preference for VBAC is remarkably consistent from the studies that are available. A recent US study on this topic reported that at 12 months postpartum, $45 \%$ of women who delivered by caesarean in their first birth wanted to have their next delivery vaginally. ${ }^{23}$ An Australian survey by Dodd et al explored the views of women in the first 6 months after delivery and found a similar preference with regard to VBAC at $41 \%$, while only $23 \%$ expressed an interest in a repeat ELSCS and $35 \%$ described themselves as being unsure. ${ }^{14}$ However, when it comes to willingness to be recruited to a future RCT of VBAC versus repeat ELSCS, the data from our study are markedly in contrast to the findings from the one other study that examined this. ${ }^{14}$ In our study, $80 \%$ of the women expressed a willingness to being involved in a future RCT in which their mode of birth would be determined by a process of randomisation. In the Australian study, only 29 women (10\%) indicated a willingness to take part in such a trial. ${ }^{14}$ While we acknowledge it is unlikely that women with a clear 
preference for ELSCS will opt in to such a study, we are of the opinion that women who are undecided (28.8\%) and those with an interest in having a VBAC (39.5\%) may remain open to being involved in such a trial, but it is difficult to estimate, with any accuracy, those that would eventually agree to randomisation in a future pregnancy. This is an important finding from our study as it supports the concept of feasibility of such an RCT in an Irish population. It is our view that prior to any future RCT on this topic, it would still be wise to perform a pilot study.

We recognise that there are certain limitations to our study. This analysis gives an overview of women's satisfaction with their CS and their preference for future mode of birth but was not able to assess the strength of this preference. Similarly, the birth preference may change over time and the data presented may not truly reflect the proportion who ultimately pursue their stated preference in a subsequent pregnancy. It is encouraging for a future RCT that $80 \%$ of our population expressed an interest in being recruited, but that statistic, as alluded to above, may change during the course of a subsequent pregnancy. It was not possible to assess the strength of the views expressed, particularly as randomly assigning mode of birth would remove the element of clinician preference and patient choice, though one could argue that agreeing to randomisation is in fact a birth preference in itself. A further limitation is that these results reflect the opinions of those who responded to the study. We are aware that the $45.2 \%$ of women who did not respond may have a different preference on mode of birth and may not be willing to participate in a trial of this nature. The aim of this study was to capture the views of women within 1 year after their first CS. A further limitation of the study is that we do not have data on the average time frame and the range of their responses and are therefore unable to comment if this would have influenced their views in any way.

In conclusion, a significant proportion of women in this cohort considered VBAC as an option for a future birth, and a majority of women stated they would consider randomisation in a potential RCT on the topic. These data indicate that randomised trial of VBAC versus repeat ELSCS would be viewed positively by women with one previous CS.

\section{Author affiliations}

${ }^{1}$ Department of Obstetrics and Gynaecology, National University of Ireland, Galway, Ireland

${ }^{2}$ Department of Obstetrics and Gynaecology, Galway University Hospitals, Galway, Ireland

${ }^{3}$ Obstetrics and Gynaecology, National Maternity Hospital, Dublin, Ireland ${ }^{4}$ School of Nursing and Midwifery, National University Of Ireland, Galway, Ireland ${ }^{5}$ UCD Perinatal Research Centre, University College Dublin, Dublin, Ireland

Acknowledgements We are grateful to all the women who participated in this study and all who were involved in collecting and analysing the data at both hospital sites.

Contributors Contribution to authorship: study concept and design: GR, JM and FM; data acquisition and analysis: GR and KCOD; drafting and critical revision of the manuscript: GR, JM, DD and FM.
Funding The authors have not declared a specific grant for this research from any funding agency in the public, commercial or not-for-profit sectors.

Competing interests None declared.

Patient consent for publication Not required.

Ethics approval Ethical approval for this study was obtained from both Galway University Hospital and the National Maternity Hospital (Galway University Hospital reference no. 1804, 13 October 2017, and National Maternity Hospital reference no. EC 37.2017, 8 January 2018).

Provenance and peer review Not commissioned; externally peer reviewed.

Data availability statement All data relevant to the study are included in the article or uploaded as supplementary information.

Open access This is an open access article distributed in accordance with the Creative Commons Attribution Non Commercial (CC BY-NC 4.0) license, which permits others to distribute, remix, adapt, build upon this work non-commercially, and license their derivative works on different terms, provided the original work is properly cited, appropriate credit is given, any changes made indicated, and the use is non-commercial. See: http://creativecommons.org/licenses/by-nc/4.0/.

\section{ORCID iD}

Gillian Ryan http://orcid.org/0000-0003-0478-1900

\section{REFERENCES}

1 Ryan GA, Nicholson SM, Morrison JJ. Vaginal birth after caesarean section: current status and where to from here? Eur J Obstet Gynecol Reprod Biol 2018;224:52-7.

2 RCOG Press. RCOG the sentinel national caesarean section audit Report- RCOG clinical effectiveness support unit, 2001. Available: https://www.rcog.org.uk/globalassets/documents/guidelines/ research-audit/nscs_audit.pdf

3 Bonzon M, Gross MM, Karch A, et al. Deciding on the mode of birth after a previous caesarean section - an online survey investigating women's preferences in Western Switzerland. Midwifery 2017:50:219-27.

4 Dodd JM, Crowther CA, Huertas E, et al. Planned elective repeat caesarean section versus planned vaginal birth for women with a previous caesarean birth. Cochrane Database Syst Rev 2013;47(Suppl 1).

5 Cheng YW, Eden KB, Marshall N, et al. Delivery after prior cesarean: maternal morbidity and mortality. Clin Perinatol 2011;38:297-309.

6 Royal College of Obstetricians and Gynaecologists. RCOG Greentop guideline No.45 birth after previous caesarean birth, 2015. Available: https://www.rcog.org.uk/en/guidelines-research-services/ guidelines/gtg45/

7 ACOG. ACOG practice Bulletin No. 205: vaginal birth after cesarean delivery. Obstet Gynecol 2019;133:e110-27.

8 Royal College of Physicians of Ireland, Institute of Obstetricians and Gynaecologists. RCPI delivery after previous caesarean section clinical practice guideline, 2013. Available: https://www.hse.ie/eng/ services/publications/clinical-strategy-and-programmes/deliveryafter-previous-caesarean-section.pdf

9 Mercer BM, Gilbert S, Landon MB, et al. National Institute of child health and human development Maternal-Fetal medicine units network. labor outcomes with increasing number of prior vaginal births after caesarean delivery. Obstet Gynecol 2008;111:285-91.

10 Uddin SFG, Simon AE. Rates and success rates of trial of labor after cesarean delivery in the United States, 1990-2009. Matern Child Health J 2013;17:1309-14.

11 Knight HE, Gurol-Urganci I, van der Meulen JH, et al. Vaginal birth after caesarean section: a cohort study investigating factors associated with its uptake and success. BJOG: Int J Obstet Gy 2014;121:183-92.

12 Colais P, Bontempi K, Pinnarelli L, et al. Vaginal birth after caesarean birth in Italy: variations among areas of residence and hospitals. BMC Pregnancy Childbirth 2018;18:383.

13 Cox KJ. Providers' perspectives on the vaginal birth after caesarean guidelines in Florida, United States: a qualitative study. BMC Pregnancy Childbirth 2011;12.

14 Dodd J, Pearce E, Crowther C. Women's experiences and preferences following caesarean birth. Aust N Z J Obstet Gynaecol 2004;44:521-4.

15 Fobelets M, Beeckman K, Faron G, et al. Vaginal birth after caesarean versus elective repeat caesarean delivery after one previous caesarean section: a cost-effectiveness analysis in four European countries. BMC Pregnancy Childbirth 2018;18:92. 
16 Law LW, Pang MW, Chung TK-H, et al. Randomised trial of assigned mode of delivery after a previous cesarean section--impact on maternal psychological dynamics. J Matern Fetal Neonatal Med 2010;23:1106-13.

17 Crowther CA, Dodd JM, Hiller JE, et al. Planned vaginal birth or elective repeat caesarean: patient preference restricted cohort with nested randomised trial. PLoS Med 2012;9:e1001192.

18 Chinkam S, Ewan J, Koeniger-Donohue R, et al. The effect of evidence-based Scripted midwifery counseling on women's choices about mode of birth after a previous cesarean. $J$ Midwifery Womens Health 2016;61:613-20.

19 Nilsson C, Lalor J, Begley C, et al. Vaginal birth after caesarean: views of women from countries with low VBAC rates. Women Birth 2017;30:481-90.
20 Blomquist J, Quiroz L, MacMillan D, et al. Mothers' satisfaction with planned vaginal and planned cesarean birth. Am J Perinatol 2011;28:383-8.

21 Shorten A, Shorten B. The importance of mode of birth after previous cesarean: success, satisfaction, and postnatal health. J Midwifery Womens Health 2012;57:126-32.

22 National Institute for Health and Care Excellence's (NICE). Guidance on elective caesarean section 2011, 2019. Available: https://www. nice.org.uk/guidance/cg132

23 Attanasio LB, Kozhimannil KB, Kjerulff KH. Women's preference for vaginal birth after a first delivery by cesarean. Birth 2019;46:51-60. 